This item was submitted to Loughborough's Research Repository by the author.

Items in Figshare are protected by copyright, with all rights reserved, unless otherwise indicated.

\title{
Analysis of nonlinear shear deformations in CFRP and GFRP textile laminates
}

PLEASE CITE THE PUBLISHED VERSION

http://www.scientific.net/AMM

PUBLISHER

(C) Trans Tech Publications, Switzerland

\section{VERSION}

AM (Accepted Manuscript)

\section{LICENCE}

CC BY-NC-ND 4.0

\section{REPOSITORY RECORD}

Ullah, Himayat, Andy R. Harland, Robert Blenkinsopp, Tim Lucas, Daniel S. Price, and Vadim V. Silberschmidt. 2019. "Analysis of Nonlinear Shear Deformations in CFRP and GFRP Textile Laminates". figshare. https://hdl.handle.net/2134/8603. 
This item was submitted to Loughborough's Institutional Repository (https://dspace.lboro.ac.uk/) by the author and is made available under the following Creative Commons Licence conditions.

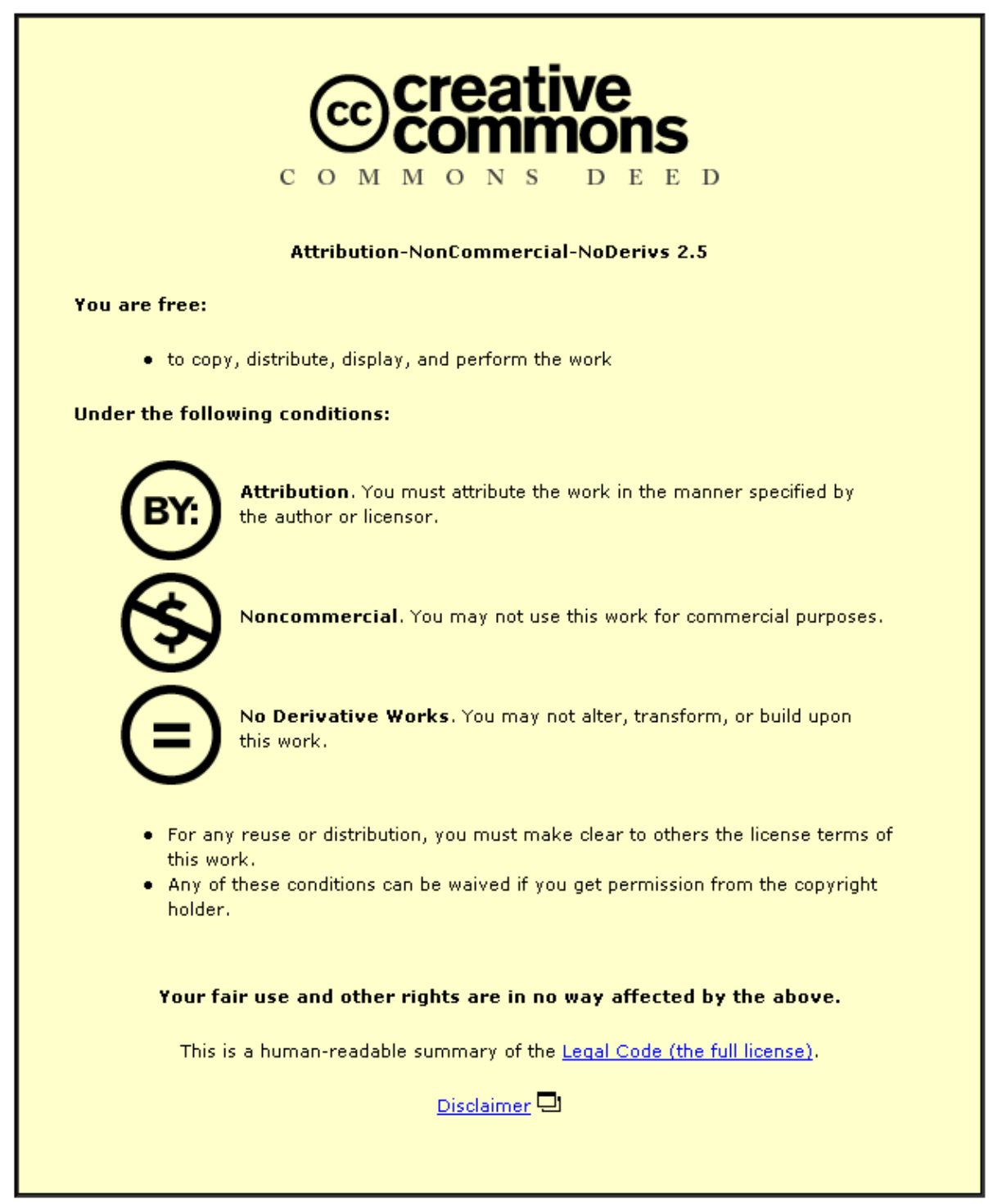

For the full text of this licence, please go to: http://creativecommons.org/licenses/by-nc-nd/2.5/ 


\title{
Analysis of nonlinear shear deformations in CFRP and GFRP textile laminates
}

\author{
HIMAYAT ULLAH ${ }^{1, a}$, ANDY R. HARLAND ${ }^{1}$, ROBERT BLENKINSOPP ${ }^{1}$, \\ TIM LUCAS ${ }^{2}$, DAN PRICE ${ }^{2}$, VADIM V. SILBERSCHMIDT ${ }^{1}$ \\ ${ }^{1}$ Wolfson School of Mechanical and Manufacturing Engineering, Loughborough University, \\ Leicestershire, LE11 3TU, UK; ${ }^{2}$ Adidas AG, Herzogenaruch, GERMANY \\ a Corresponding author: Ashby Road, Loughborough, Leics., LE11 3TU, UK \\ Phone: +44-1509-227534. Fax: +44-1509-227502. \\ aemail: $\underline{\text { H.Ullah@lboro.ac.uk }}$
}

Keywords: Woven Composites, Material non-linearity, Finite element modeling, Tensile tests

\begin{abstract}
Carbon fibre-reinforced polymer (CFRP) and glass fibre-reinforced polymer (GFRP) woven composites are widely used in aerospace, automotive and construction components and structures thanks to their lower production costs, higher delamination and impact strengths. They can also be used in various products in sports industry. These products are exposed to different inservice conditions such as large tensile and bending deformations. Composite materials, especially $\pm 45^{\circ}$ symmetric laminates subjected to tensile loads, exhibit significant material as well as geometric non-linearity before damage initiation, particularly with respect to shear deformations.

Such a nonlinear response needs adequate means of analysis and investigation, the major tools being experimental tests and numerical simulations. This research deals with modelling the nonlinear deformation behaviour of CFRP and GFRP woven laminates subjected to in-plane tensile loads. The mechanical behaviour of woven laminates is modelled using nonlinear elasto-plastic as well as material models for fabrics in commercial finite-element code Abaqus. A series of tensile tests is carried out to obtain an in-plane full-field strain response of [+45/-45 $]_{2 \mathrm{~s}}$ CFRP and GFRP laminates using digital image correlation technique according to ASTM D3518/D3518M-94. The obtained results of simulations are in good agreement with experimental data.
\end{abstract}

\section{Introduction}

Composite materials, especially carbon fibre-reinforced plastics (CFRP) and glass fibre-reinforced plastics (GFRP) have found many applications in aerospace, automotive, medical and construction components and structures due to their better specific strength and stiffness. Woven-fabric composite laminates offer a number of attractive properties compared to their unidirectional-tape counterparts such as relatively low production costs, better drapability, good resistance to fracture and transverse rupture due to weaving resistance, and high impact strength [1,2]. These properties have attracted the sports industry to incorporate woven CFRP laminates in the design of sports products. Such products could be subjected to large-deflection tensile and bending loads in service conditions. These loads generate high local stresses and strains leading to material as well as geometric non-linearity, and subsequent damage of the textile laminates. Damage evolution results in significant reduction of in-service mechanical properties and leads to a loss of structural integrity of the composite sports products with time.

Experimental testing of CFRP and GFRP off-axis textile laminates such as $\pm 45^{\circ}$ exhibited highly nonlinear behaviour as compared to their on-axis counterparts. Both CFRP and GFRP $\pm 45^{\circ}$ specimens exhibited a large-deformation nonlinear behaviour and as high levels of strain to failure as $35 \%$ and $30 \%$, respectively, as illustrated in Fig.1. The laminates were still able to carry a load 
after the damage initiated at yield point. This behaviour needs further investigation to take full advantage of the composite load-carrying capability before their ultimate fracture. A great amount of research is focused on the linear quasi-brittle behaviour of on-axis textile laminates such as $0^{\circ}$ and $90^{\circ}$, whereas the nonlinear behaviour of off-axis woven composites has been studied by few researchers. Nonlinear constitutive material models based on continuum plasticity were developed in [3-8] to characterise the behaviour of woven composite laminates. According to Sun and Tao [9], the non-linear behaviour of composite laminates results from material plasticity, progressive damage in the laminate and geometric non-linearity. Composite laminates subjected to shear and transverse loads also exhibit significant material non-linearity. They investigated that plasticity originates solely from the matrix cracking. Ogihara and Reifsnider [4] studied the non-linear behaviour in textile glass/epoxy composites and observed that some plasticity also occur in the fibres. Hochard et al. [6] illustrated that inelastic strains in $\pm 45^{\circ}$ laminates resulted from a slipping process occurring between fibres and matrix as the result of damage. Hufner and Accorsi [7] discussed that the non-linearity in glass woven fabric resulted from matrix cracking followed by fibre trellising till the fibre failure. Fibre trellising occurs when the fibres re-orient towards the direction of load and the angle between warp and weft fibres changes from $90^{\circ}$. Therefore, when off-axis $\pm 45^{\circ}$ laminates are subjected to tensile loads, the warp and weft direction yarns rotate with respect to each other and result in in-plane shear. A reliable and promising approach to investigate the material as well as geometric nonlinearities in these laminates is to employ isotropic plasticity and fabric material constitutive descriptions in finite element models.

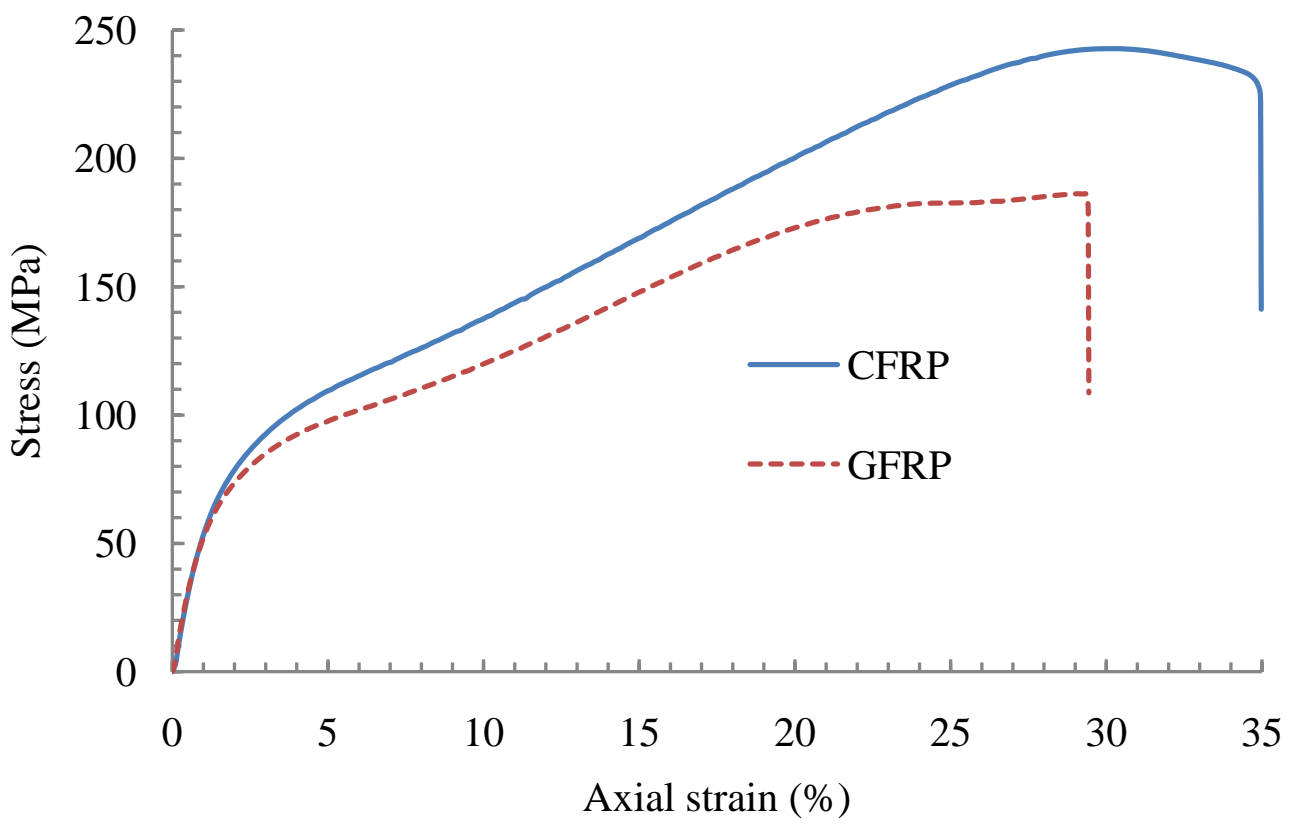

Fig. 1. Nonlinear behaviour of CFRP and GFRP specimens.

In this work, non-linearity in CFRP and GFRP textile laminates due to material plasticity as well as geometry was studied using experimental and numerical methods. Experimental tensile tests on $\pm 45^{\circ}$ woven specimens were conducted with digital image correlation (DIC) technique for full-field two-dimensional deformation and strain measurements. The macro-mechanical behaviour of woven laminates was modelled using nonlinear isotropic elasto-plastic and material models for fabrics in commercial finite-element code Abaqus. FE models based on the fabric constitutive material model were capable of predicting nonlinear large strain behaviour of woven laminates up to the laminate rupture with a reasonable level of confidence. Although plasticity-based FE models for textile laminates had been developed earlier, the application of fabric material model in this work was a recent one. 


\section{Experimental tests using digital image correlation method}

To investigate the non-linearity and in-plane shear response of $\pm 45^{\circ} \mathrm{CFRP}$ and GFRP, tensile tests were conducted following ASTM D3518/D3518M-94 [10]. Although the standard outlines the procedure for using strain gauges in longitudinal and transverse directions, they provide the local strain data. Therefore, an ARAMIS digital image correlation (DIC) system was used to obtain the full-field in-plane displacement and strain data. Digital image correlation is a non-contacting fullfield deformation and strain measurement technique that uses no mechanical gauges and requires no mechanical interaction with the specimen; it was developed by Sutton et al. [11, 12]. DIC technique has already been used by $[13,14]$ to characterise the material behaviour of textile laminates. Instron 5569 test machine was used, while two high speed digital cameras took photographs of the specimen at frequencies ranging from 10 to $2000 \mathrm{~Hz}$. The Instron machine had an integrated load cell, and load measurements were synchronised to each photograph at each time interval.

(a)
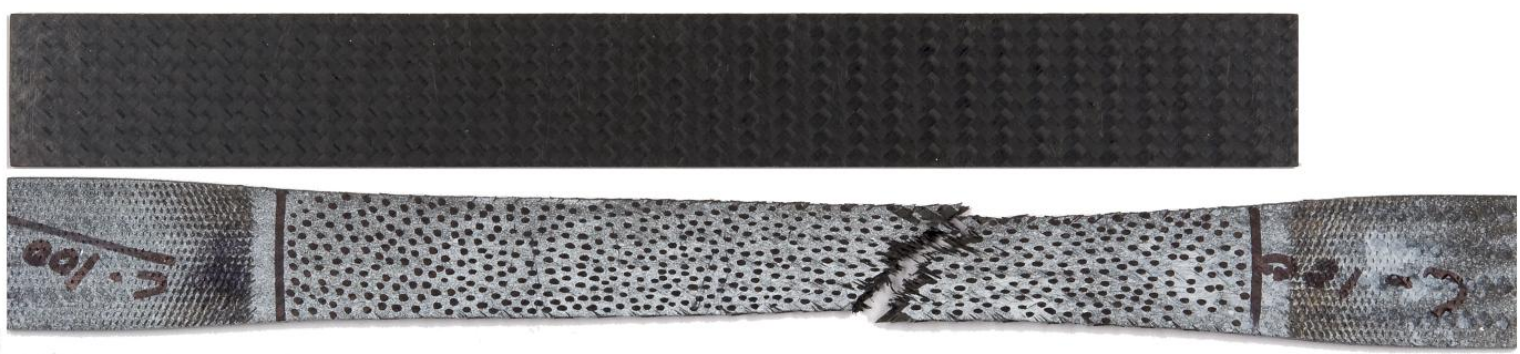

(b)
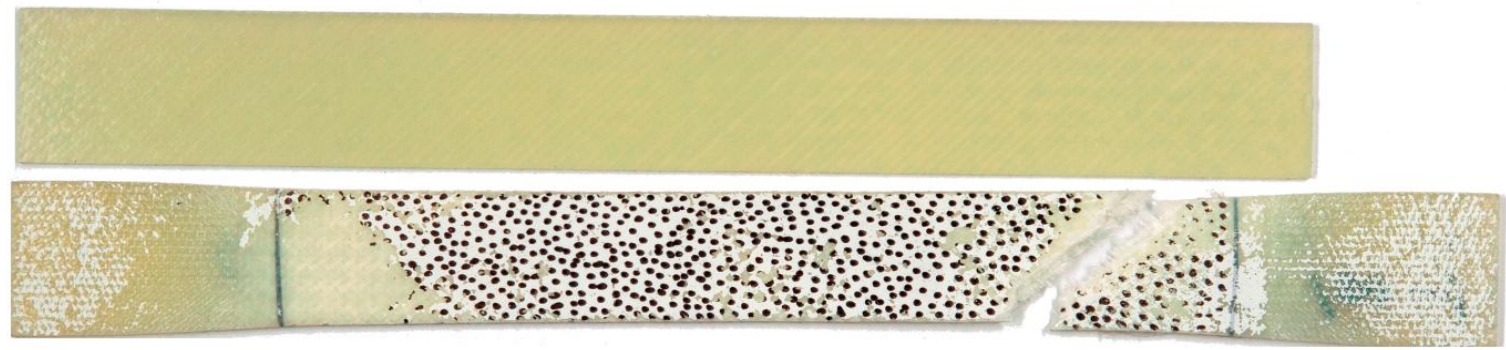

Fig. 2. Specimens and shear fracture of twill $2 / 2[+45 /-45]_{2 s}$ woven laminates in tensile tests:

(a) CFRP; (b) GFRP

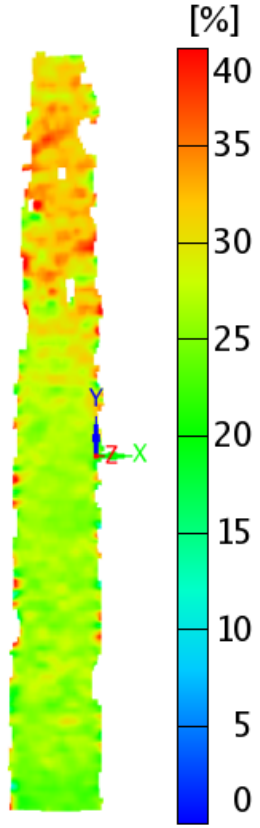

(a)

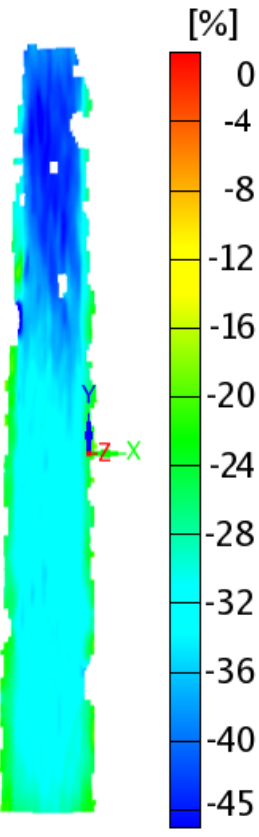

(b)

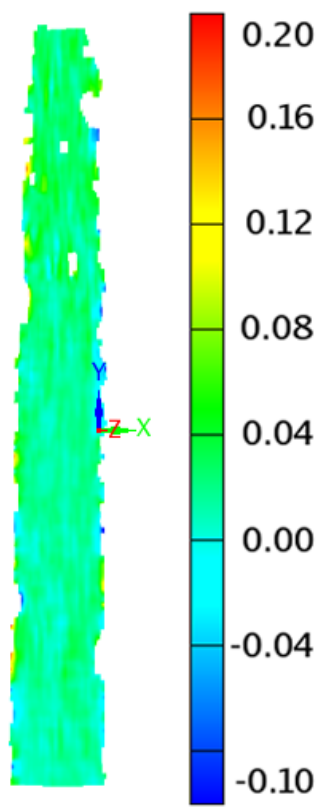

(c)

Fig. 3. Digital images of (a) major; (b) minor; and (c) shear strain for CFRP sample at $11.6 \mathrm{kN}$ load 
Tensile tests were carried out on the Instron machine with in-plane full-field strain registration of [+45/-45 $]_{2 \mathrm{~s}}$ CFRP and GFRP laminates using ARAMIS system. CFRP and GFRP specimens were fabricated from carbon-fibre fabric and glass-fibre fabric respectively, woven in $2 / 2$ twill reinforcement in thermoplastic polyurethane (TPU) polymer. Samples were tested at crosshead speed of $100 \mathrm{~mm} / \mathrm{min}$ equivalent to a strain rate of $0.014 / \mathrm{sec}$. Rectangular specimens of $200 \mathrm{~mm}$ length, $25 \mathrm{~mm}$ width and $2 \mathrm{~mm}$ thickness were prepared, each laminate having $0.25 \mathrm{~mm}$ thick eight plies. The gauge length for both types of samples was kept to $120 \mathrm{~mm}$. Nonlinear engineering stress-strain behaviour of CFRP and GFRP specimens is presented in Fig. 1. Axial strains were measured using extensometer due to some slippage of samples at their ends in the Instron machine's wedge grips as can be observed in Fig. 2. At about $1 \%$ strain, both materials start to yield due to matrix cracking, and the density of matrix cracks keeps increasing with increasing load resulting in a non-linear response. The density of matrix cracks reaches a saturation level at about $7 \%$ strain, where the non-linearity from matrix cracking is no longer prevalent. Now the material behaviour is controlled by fibre trellising, and the non-linearity is due to fibre reorientation towards the loading direction. Fibre trellising continues until about $28 \%$ and $23 \%$ strains for CFRP and GFRP specimens, respectively, where eventually necking and the fibre failure begins. The final nonlinearity is a likely result of random fibre failure over a range of axial strain. Both specimens were sprayed with white paint, and then black speckles were marked on them to provide contrast necessary for the image correlation as shown in Fig. 2. The studied zone has the length of $120 \mathrm{~mm}$ and covered $25 \mathrm{~mm}$ width of the specimens. Digital images of the specimens were taken at 50 frames per second during loading by two high-speed 1 Megapixels cameras. Major, minor and shear strain contour plots of CFRP sample are shown in Fig. 3. The corresponding load levels are slightly less than the failure load in each case. It is noted that the major and minor strain contours vary, and shear strain plots are almost uniform. The empty regions in the picture represent the flaking of paint, which was speckled, and thus the data at these regions was not collected. Similarly, major, minor and shear strain contour plots for GFRP sample before ultimate fracture are shown in Fig. 4. The contour plots have no voids as the speckles did not flake off the sample till the specimen fracture. Since the paint was too fragile, the speckles flaked off from the laminate at the time of specimen fracture as can be seen in Fig. 2(b).

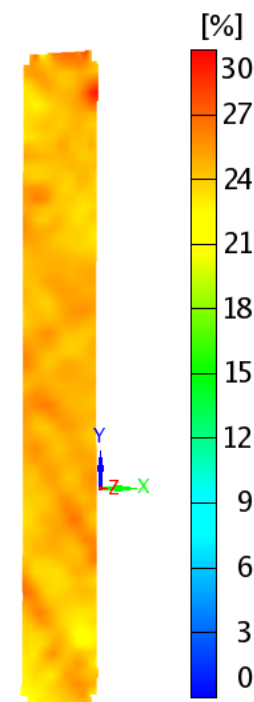

(a)

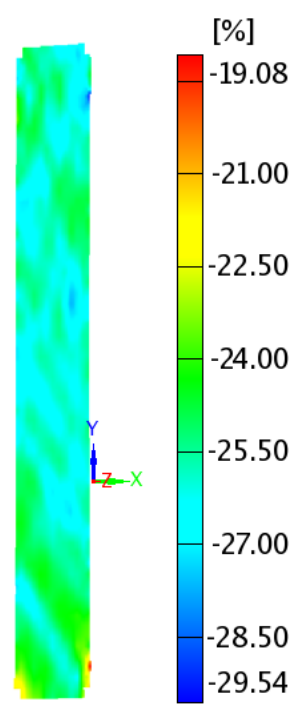

(b)

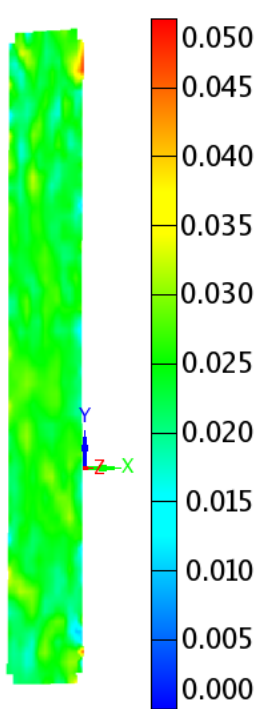

(c)

Fig. 4. Digital images of (a) major; (b) minor; and (c) shear strain for GFRP sample at $9.3 \mathrm{kN}$ load

\section{Finite-element modelling}

Finite element models were developed to investigate large-deflection shear non-linearity of tested CFRP and GFRP laminates in the commercial FE package ABAQUS/Explicit, for better numerical convergence. Two FE models based on isotropic elasto-plasticity and fabric material representing 
the tensile tests of each type of CFRP and GFRP specimens were developed. Composite laminates were meshed with two-dimensional plane-stress reduced integration and hourglass control CPS4R elements, using the structured meshing technique with an element size of $1 \mathrm{~mm}$ on each side. The material's elasto-plastic behaviour was defined by inputting the true stress-strain data obtained from the nominal stress-strain test data for both types of specimens. A progressive-damage behaviour of off-axis GFRP samples was studied in [15] by implementing isotropic softening plasticity model with viscous regularisation. The model of fabric material is anisotropic and nonlinear phenomenological model that captures the mechanical response of a woven fabric made of yarns in the warp and weft directions [16]. Fabric material models require stress-strain data in longitudinal, transverse and shear directions, which is obtained with the DIC test method. Fixed boundary conditions were applied at one end of the laminate whereas the other end is subjected to displacement-controlled loads. Quasi-static analyses of both types of FE models were carried out with activating nonlinear geometrical effects. The obtained results for CFRP and GFRP laminates are compared with tests in Figs. 5 and 6, respectively.

\section{Discussion of results and conclusions}

Numerical results of simulations of the large-deflection shear non-linear behaviour of CFRP and GFRP laminates and comparison with experimental tests are presented in this section. Both CFRP and GFRP materials had the same TPU matrix. Although the non-linearity was usually attributed to matrix cracking, the fibres also contributed to the nonlinear behaviour as the strain-to-break for CFRP specimens was 35\%, which was higher than $30 \%$ for GFRP as shown in Fig. 1. Further, CFRP demonstrated a more pronounced neck formation and trellising behaviour than GFRP before ultimate fracture as carbon fibres were stronger than glass ones and the resin underwent more plastic deformation as illustrated in Fig. 2.

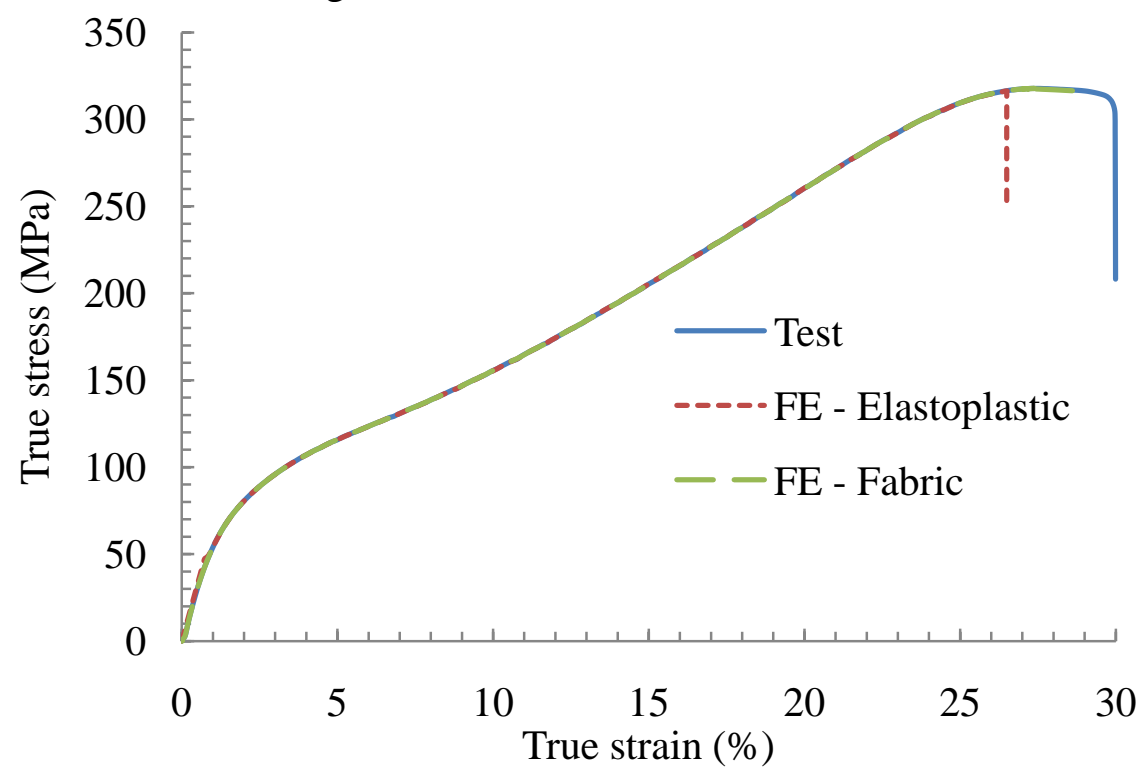

Fig. 5. Comparison of CFRP test and finite element simulations

Full-field strain measurements on the surfaces of CFRP and GFRP textile composite samples under tension proved to be a useful tool in studying their mechanical behaviour on the macro-scale, providing validation data for FE modelling of the composite. As the specimens were loaded axially and stretched upwards, the maximum strains occurred at the top of the specimens. However, the strains at some middle regions were also higher which might be due to more compliant regions such as matrix, or yarns aligned across the loading directions. Magnitudes of major (axial) and minor (transverse) strains were almost the same for both specimens at specific regions, which indicate that the specimen failure is due to large shear deformations. The advantages of DIC method were the availability of the full strain/displacement field, as well as the ability to experimentally determine 
all components of strain at any point in the region of interest. If mechanical gauges were used, these data had required several tests with different gauges.

Our simulations showed very good agreement with experimental results indicating that the numerical models were capable to reproduce the non-linear behaviour of off-axis laminates as illustrated in Figs. 5 and 6. In simulations of both CFRP and GFRP with elasto-plastic material models, the solution diverged when the material behaved fully plastic, i.e. material softened without any further strain hardening, as illustrated in Figs. 5 and 6. Such material's behaviour with stiffness degradation is also represented in [15]. Fabric material models followed the full non-linear stressstrain behaviour till the laminate fracture. Therefore, the constitutive models of fabric material were capable to predict both the material as well as geometric non-linearity in woven laminates.

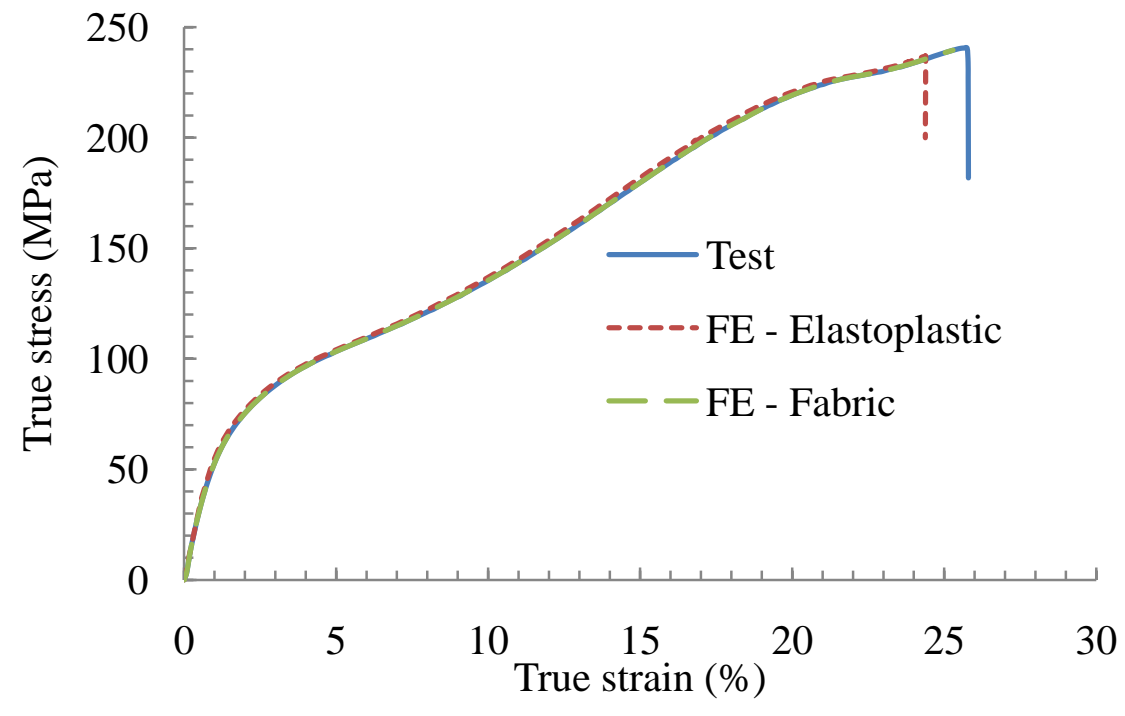

Fig. 6. Comparison of GFRP test and finite element simulations

\section{References}

[1] C. Hochard, J. Payan, C. Bordreuil, International Journal of Fatigue, 28 (2006) 1270-1276.

[2] G. Ernst, M. Vogler, C. Hühne, R. Rolfes, Composites Science and Technology, 70 (2010) 6172.

[3] G. Odegard, K. Searles, M. Kumosa, Composites Science and Technology, 61 (2001) 25012510.

[4] S. Ogihara, K.L. Reifsnider, Applied Composite Materials, 9 (2002) 249-263.

[5] A. Tabiei, I. Ivanov, International Journal of Non-Linear Mechanics, 39 (2004) 175-188.

[6] C. Hochard, S. Miot, N. Lahellec, F. Mazerolle, M. Herman, J.P. Charles, Composites Part A, 40 (2009) 1017-1023.

[7] D.R. Hufner, M.L. Accorsi, Composite Structures, 89 (2009) 177-185.

[8] L. Xing, K.L. Reifsnider, X. Huang, Composites Science and Technology, 69 (2009) 780-784.

[9] C.T. Sun, J. Tao, Composites Science and technology, 58 (1998) 1125-1136.

[10] ASTM D3518/D3518M-94: Standard Test Method for In-Plane Shear Response of Polymer Matrix Composite Materials by Tensile Test of a $\pm 45^{\circ}$ Laminate (2007).

[11] M.A. Sutton, W.J. Wolters, W.H. Peters, W.F. Ranson, S.R. McNeill, Image and Vision Computing, 1 (1983) 133-139.

[12] T.C. Chu, W.F. Ranson, M.A. Sutton, Experimental Mechanics, 25 (1985) 232-244.

[13] D. Ivanov, S. Ivanov, S. Lomov, I. Verpoest, Optics and Lasers in Engineering, 47 (2009) 360370.

[14] S.V. Lomov, D.S. Ivanov, I. Verpoest, M. Zako, T. Kurashiki, H. Nakai, J. Molimard, A. Vautrin, Composites Part A, 39 (2008) 1218-1231.

[15] F.P. Van Der Meer, L.J. Sluys, Journal of Composite Materials, 43 (2009) 2131.

[16] Hibbit, Karlsson, Sorensen, in, ABAQUS User's Manual, Version 6.10, Michigan, USA, 2010. 